\title{
A study on the effect of macroeconomics instability index on private investment in Iran
}

\author{
Abdolmajid Ahangari* and Aziz Saki
}

Department of Economics and Social Science, Ahvaz Shahid Chamran University, Ahvaz, Iran

\begin{tabular}{|c|c|}
\hline ART I C L E I N F O & AB S T RAC T \\
\hline $\begin{array}{l}\text { Article history: } \\
\text { Received March 28, } 2012 \\
\text { Accepted } 17 \text { June } 2012 \\
\text { Available online } \\
\text { June } 182012 \\
\text { Keywords: } \\
\text { Macroeconomics instability index } \\
\text { Private investment } \\
\text { Econometrics model }\end{array}$ & $\begin{array}{l}\text { In this paper, we perform an empirical study to investigate the impact of economical stability } \\
\text { on the amount of investment coming from the private sector. We calculate macroeconomics } \\
\text { instability index (MII) using the existing methods in the literature. We have also used Glezakos } \\
\text { (1973) method [Glezakos,C.(1973). Export instability and economic growth: A statistical } \\
\text { verification. Economic Development and Cultural Change, 21(3), 670-678.], which considers } \\
\text { long-term deviation of real values as instability index. Therefore, we use four variables of } \\
\text { inflation rate (TINF), the ratio of budget deficit on growth domestic product (GDP) (TBD), } \\
\text { foreign debt on GDP (TFD) and the ratio of actual currency rate on nominate currency (TRO). } \\
\text { The preliminary results show that the short-term changes on logarithm of investment from } \\
\text { private sector (LNIP) with one lag and logarithm of value added (LNIV) have positive impact } \\
\text { on LNIP. In addition, any short term changes on logarithm of MII (LNMII) has negative and } \\
\text { meaningful impact on LNIP and approximately 0.67 percent of difference between the actual } \\
\text { and long term are discounted in each period. The results indicate that instability index has } \\
\text { negative effect even in short term on Iran's industry. This shows the relevant importance of } \\
\text { instability on economy. }\end{array}$ \\
\hline
\end{tabular}

\section{Introduction}

Macroeconomic stability plays an important role on economy, a stable economy grows faster when there is no chaos in economical figures such as inflation, currency exchange rate, etc. This is a fact that many long terms investment plans are executed by private sectors when there is a peace of mind specially when the investment is performed by private sector. During the past few years, there have been tremendous works on measuring the effect of macro economical instability on private investment. Andrés \& Doménech (2006) analyzed the impact of the fiscal structure on the trade-off between inflation and output stabilization induced by technological shocks in a DGE. They used model with nominal and real rigidities, which also integrated some fiscal variables and a target on the debt to output ratio. The channels through which fiscal policy influences macroeconomic stability incorporate supply-side impacts of the procyclical behavior of public spending induced by fiscal 
rules, distortionary taxes and the conventional impact of automatic stabilizers operating through disposable (permanent) income.

The paper investigated these channels and came to a conclusion that, on contrary to RBC models, distortionary taxes will likely reduce output volatility compared with lump-sum taxes when substantial rigidities are present. They also studied the stabilization impact of alternative (distortionary) tax structures and reported that these were only relevant if substantial rigidities were present.

Chang et al. (2011) investigated the relationship between interest-rate feedback rules and macroeconomic stability when there are some transaction costs. They explained that with the Simstype transaction-cost technology, a passive, rather than an active, interest-rate rule could generate a stabilizing impact against belief-driven fluctuations if both the intertemporal elasticity of substitution with respect to consumption and the sensitivity of the transaction costs with respect to the velocity of money were low. Pesola (2011) investigated the joint effect of financial fragility and macroeconomic shocks on bank loan losses by looking at some evidence from Europe.

Morgan (2011) described the contribution that macroeconomic policy could make to promote a rebalancing of growth to a better rate of growth. His model represented a substantial departure from the old uses of macroeconomic policy to stabilize the economic cycle and achieved stable and low inflation. The evidence recommended that macroeconomic policy could successfully contribute to growth rebalancing.

According to Morgan (2011) policy measures not only could impact aggregate demand directly, but also it could influence it indirectly via their "microeconomic" effects on private sector behavior such as the household savings rate. Morgan emphasized that in the long-term fiscal policy should be balanced to keep government debt stability and avoid crowding out of private investment. There are, however, other studies suggesting that most of the needed stimulus must be provided by monetary policy, with only a supplementary impact to be played by fiscal policy (Glezakos, 1973; Agenor, 2000).

Cox and Harvie (2011) explained the necessity of increased global demand for energy and other resources, primarily from the rapidly developing economies of India, Brazil and China and the opening up of global resource markets to global investors has resulted in substantial turbulence in resource prices for the past few years. The recent changes in resource prices either negatively to positively play important role on both resource importing and exporting economies. Cox and Harvie (2011) developed a generic analytical framework to appraise economic outcomes in the wake of a resource price boom for a resource producing and exporting economy.

The proposed study of this paper presents an econometrics method for measuring the impact of macroeconomics instablity index on private investment in Iran. The organization of this paper first presents details of our proposed model in section 2 and the results of our findings are given in section 3. The paper ends with concluding remarks to summarize the contribution of the paper.

\section{Macroeconomics Instability Index (MII) in Iran}

In this study, to calculated macroeconomics instability index (MII) we use the method proposed by Fischer (1991), Fischer and Modigiliani (1993) and Bleaney (1996). We have also used Glezakos (1973) method, which considers long-term deviation of real values as instability index. Therefore, we use four variables of inflation rate (TINF), the ratio of budget deficit on growth domestic product (GDP) (TBD), foreign debt on GDP (TFD) and the ratio of actual currency rate on nominate currency (TFD). Then we do regression analysis on long term of each item and estimate long term deviation. We use time series analysis using the following, 
$T X_{t n}=a_{0}+a_{1} t+a_{2} t^{2}+a_{3} t^{3}+\ldots+a_{n} t^{n}+e_{t}$,

where $T X_{t n}$ is the estimated value of $X_{t}, t$ represents time and $e_{t}$ is the error term. We have used historical data from 1963 to 2003 to perform least square technique (OLS), which yields the following,

$$
\begin{aligned}
& T B D_{t n}=1.43 t-0.36 t^{2}+0.046 t^{3}-0.003 t^{4}+5.8 \times 10^{-6} t^{5}-4.88 \times 10^{-8} t^{6}+e_{t} \\
& \begin{array}{lllll}
(-2.00)(2.03)(-1.95) & (1.73) \quad(1.39)
\end{array} \\
& \text { TINF }_{t n}=15.14-11.84 t+2.64 t^{2}-0.23 t^{3}+0.009 t^{4}-1.8 \times 10^{-4} t^{5}+1.4 \times 10^{-7} t^{6}+e_{t} \\
& \begin{array}{llllll}
(1.75) & (-1.84)(1.92) & (-1.98) \quad(2.00) \quad(-1.78) \quad(1.41) \quad R^{2}=0.62
\end{array} \\
& T R O_{t n}=-74.35+182.73 t-46.13 t^{2}+4.52 t^{3}-0.19 t^{4}+0.003 t^{5}-2.92 \times 10^{6} t^{6}+e_{t} \\
& \begin{array}{lllllll}
(-3.44) & (3.66) & (-3.79) & (3.72) & (-3.32) & (2.61) & (-0.65)
\end{array} R^{2}=0.81 \\
& T F D_{t n}=2.59-2.26 t+0.55 t^{2}-0.049 t^{3}+0.002 t^{4}-3.87 \times 10^{6} t^{5}+2.87 \times 10^{8} t^{6}+e_{t} \\
& \begin{array}{lllllll}
(-4.52)(4.83)(-5.06) & (4.97) & (-4.03) & (2.86) & (-5.06) & R^{2}=0.81
\end{array}
\end{aligned}
$$

In eq. (2) to Eq. (5) $T B D_{t n}$ is budget deficit to GDP, $T I N F_{t n}$ is the inflation rate, $T R O_{t n}$ is the margin of currency, $T F D_{t n}$ is the foreign debt to GDP and finally $e_{t}$ is the error term. Table 1 shows the information used for the regression analysis.

\section{Table 1}

Historical data for Macroeconomics Instability Index estimation (All figures are in percentage)

\begin{tabular}{llllllllll}
\hline Year & TBD & TINF & TRO & TFD & Year & TBD & TINF & TRO & TFD \\
\hline 1963 & 2.04 & 0.6 & 128.82 & 0.09 & 1983 & 9.79 & 14.8 & 467.32 & 0.001 \\
1964 & 2.90 & 4 & 115.23 & 0.188 & 1984 & 5.82 & 10.4 & 678.30 & 0.0019 \\
1965 & 1.58 & 0 & 115.30 & 0.298 & 1985 & 4.63 & 6.9 & 308.56 & 0.0027 \\
1966 & 0.19 & 1 & 111.49 & 0.398 & 1986 & 9.32 & 23.7 & 374.79 & 0.0031 \\
1967 & 2.33 & 0.5 & 109.03 & 0.450 & 1987 & 9.13 & 27.7 & 512.23 & 0.0043 \\
1968 & 3.43 & 1 & 110.60 & 0.517 & 1988 & 9.84 & 28.9 & 402.43 & 0.001 \\
1969 & 4.29 & 3 & 112.94 & 0.654 & 1989 & 4.38 & 17.4 & 478.54 & 0.0012 \\
1970 & 3.71 & 1 & 112.46 & 1.461 & 1990 & 1.18 & 9 & 386.96 & 0.046 \\
1971 & 4.77 & 5.6 & 111.74 & 1.606 & 1991 & 2.16 & 20.7 & 300.02 & 0.266 \\
1972 & 9.16 & 6.3 & 108.56 & 1.625 & 1992 & 1.18 & 24.3 & 236.74 & 0.140 \\
1973 & 3.81 & 11.4 & 109.80 & 2.046 & 1993 & 0.32 & 22.9 & 161.05 & 0.249 \\
1974 & 5.08 & 15.6 & 108.90 & 3.268 & 1994 & 0.33 & 35.2 & 148.70 & 0.162 \\
1975 & 7.92 & 9.9 & 110.07 & 4.706 & 1995 & 0.29 & 49.4 & 139.79 & 0.059 \\
1976 & 5.04 & 16.5 & 113.32 & 3.336 & 1996 & 0.99 & 28.9 & 147.81 & 0.092 \\
1977 & 9.31 & 24.9 & 113.27 & 3.548 & 1997 & 0.12 & 17.3 & 158.98 & 0.150 \\
1978 & 12.16 & 10 & 129.26 & 2.993 & 1998 & 1.89 & 17.8 & 119.88 & 0.171 \\
1979 & 5.82 & 11.3 & 226.31 & 2.371 & 1999 & 0.10 & 20.1 & 109.49 & 0.159 \\
1980 & 16.99 & 23.6 & 331.70 & 2.078 & 2000 & 0.69 & 12.6 & 101.36 & 0.611 \\
1981 & 13.54 & 23 & 504.28 & 1.692 & 2001 & 0.39 & 11.4 & 101.09 & 0.747 \\
1982 & 8.92 & 19.2 & 568.18 & 0.0012 & 2002 & 2.21 & 15.8 & 100.76 & 2.777 \\
\hline
\end{tabular}

Ref: Central bank of Iran (http://www.cbi.ir)

In order to calculate Macroeconomics Instability Index we use the following,

$$
\begin{aligned}
& I B D_{t n}=B D_{t}-T B D_{t n}, \\
& I I N F_{t n}=I N F_{t}-T I N F_{t n},
\end{aligned}
$$


1942

$$
\begin{aligned}
& I R O_{t n}=E R O_{t}-T R O_{t n}, \\
& I F D_{t n}=F D_{t}-T F D_{t n},
\end{aligned}
$$

where $I B D_{t n}$ and $B D_{t}$ are deviations of budget deficit compared with GDP and budget deficit compared with GDP, respectively. In addition, $I I N F_{t n}$ and $I N F_{t}$ are instability of inflation rate and inflation rate, respectively. $I R O_{t n}$ and $E R O_{t}$ are instability in margin of currency and margin of currency, respectively. Finally, $I F D_{t n}$ and $F D_{t}$ are instability on foreign debt to GDP and foreign debt to GDP, respectively. In order to calculate the Macroeconomics Instability Index $\left(M I I_{t n}\right)$ we use a simple moving average based on Eq. (10) and the results are summarized in Table 2.

$$
M I I_{t n}=\frac{\sum\left(I I N F_{t n}, I B D_{t n}, I F D_{t n}, I R O_{t n}\right)}{N} .
$$

\section{Table 2}

The summary of the results of our calculation for $\mathrm{MII}_{t n}$

\begin{tabular}{llllllllllll}
\hline Year & $\mathrm{IRO}_{\mathrm{tn}}$ & $\mathrm{IINF}_{\mathrm{tn}}$ & $\mathrm{IBD}_{\mathrm{tn}}$ & $\mathrm{IFD}_{\mathrm{tn}}$ & $\mathrm{MII}_{\mathrm{tn}}$ & Year & $\mathrm{IRO}_{\mathrm{tn}}$ & $\mathrm{IINF}_{\mathrm{tn}}$ & $\mathrm{IBD}_{\text {tn }}$ & $\mathrm{IFD}_{\text {tn }}$ & $\mathrm{MII}_{\mathrm{tn}}$ \\
\hline 1963 & 97.60 & -5.12 & 1.20 & -0.11 & 23.39 & 1983 & -4.28 & -1.66 & -0.21 & 0.00 & -1.54 \\
1964 & -34.08 & 3.65 & 1.19 & 0.04 & -7.30 & 1984 & 201.79 & -6.70 & -3.59 & -0.03 & 47.86 \\
1965 & -77.56 & 2.04 & -1.40 & 0.09 & -19.21 & 1985 & -160.78 & -11.06 & -4.16 & -0.06 & -44.02 \\
1966 & -77.29 & 3.31 & -4.49 & 0.09 & -19.60 & 1986 & -76.57 & 4.70 & 3.24 & $0.09-$ & -17.18 \\
1967 & -49.11 & 1.66 & -0.86 & 0.05 & -12.06 & 1987 & 87.65 & 7.49 & 1.97 & -0.12 & 24.25 \\
1968 & -6.40 & 0.17 & 0.75 & 0.01 & -1.37 & 1988 & 10.70 & 7.38 & 6.89 & -0.13 & 6.21 \\
1969 & 35.91 & -0.23 & 2.16 & -0.04 & 9.45 & 1989 & 122.56 & -5.46 & 0.01 & $0.12-$ & 29.25 \\
1970 & 66.33 & -4.73 & 1.01 & -0.06 & 15.64 & 1990 & 66.14 & -15.15 & -3.19 & -0.09 & 11.93 \\
1971 & 82.62 & -2.50 & 1.55 & -0.08 & 20.40 & 1991 & 10.18 & -4.60 & -0.84 & 0.01 & 1.19 \\
1972 & 80.37 & -3.88 & 6.99 & -0.08 & 20.85 & 1992 & -29.65 & -1.90 & -1.00 & 0.04 & -8.13 \\
1973 & 66.30 & -0.50 & -2.16 & -0.07 & 15.89 & 1993 & -92.24 & -3.87 & -1.19 & 0.14 & -24.29 \\
1974 & 35.30 & 2.36 & -2.88 & -0.04 & 8.69 & 1994 & -103.80 & 8.29 & -1.09 & 0.18 & -24.10 \\
1975 & -5.83 & -4.30 & -1.38 & 0.01 & -2.88 & 1995 & -33.24 & 22.83 & -0.41 & 0.17 & -2.66 \\
1976 & -53.73 & 1.67 & -4.17 & -0.02 & -14.06 & 1996 & -34.55 & 3.21 & -0.80 & 0.19 & -7.99 \\
1977 & -109.99 & 9.69 & -1.22 & 0.06 & -25.36 & 1997 & -47.78 & -6.99 & 0.64 & 0.15 & -13.50 \\
1978 & -151.39 & -5.40 & 1.85 & 0.09 & -38.71 & 1998 & 13.82 & -4.61 & 2.80 & -0.03 & 3.00 \\
1979 & -109.18 & -4.20 & -4.93 & 0.10 & -29.55 & 1999 & 111.21 & -0.06 & 0.13 & -0.47 & 27.71 \\
1980 & -52.73 & 8.01 & 6.46 & 0.11 & -9.54 & 2000 & 77.16 & -5.13 & 0.21 & -0.26 & 17.99 \\
1981 & 79.58 & 7.26 & 3.34 & 0.11 & 22.57 & 2001 & 98.16 & -4.00 & -0.98 & -0.99 & 23.05 \\
1982 & 114.00 & 3.19 & -1.37 & 0.03 & 28.96 & 2002 & -165.61 & 2.25 & 0.11 & 1.96 & -40.33 \\
& & & & & & 2003 & 18.38 & 2.90 & -0.17 & -0.73 & 5.09 \\
\hline
\end{tabular}

\section{The proposed model}

The proposed model of this paper uses different macro economics factors to investigate MII such as investment from private sector (IP), government's investment (IH), income from oil and gas export (IF), value added in sector of Industry (IV), banks' credits (IM) and a dummy variable associated with the changes in political changes from 1963 to 2003. The dummy variable is associated with the revelation of 1979 held in Iran where there was a revolution on the government of Iran. The following shows the proposed model in linear form,

$$
I P_{t}=\alpha_{0}+\alpha_{1} M I I+\alpha_{2} I H_{t}+\alpha_{3} I F_{t}+\alpha_{4} I M_{t}+\alpha_{5} I V_{t}+\alpha_{6} D R \text {. }
$$

We could also use the logarithmic form of the equation as follows,

$$
L N I P_{t}=\beta_{0}+\beta_{1} L N M I I_{t}+\beta_{2} L N I H_{t}+\beta_{3} L N I F_{t}+\beta_{4} L N I M_{t}+\beta_{5} L N I V_{t}+\beta_{6} D R .
$$




\subsection{Stationary test analysis}

The results of our investigation shows that all variables are non-stationary since Dicky-Fuller and Augmented Dicky-Fuller calculated t values are less than critical Mackinnon value. Therefore, the null hypothesis for having root-one cannot be rejected. However, our results show that all variables become stationary after getting one difference. Therefore, all variables are considered as I(1). Table 3 and Table 4 demonstrate the results of applying Augmented Dicky-Fuller before and after getting difference.

\subsection{Johansen-Juselius maximum likelihood co-integration test}

In order to use Johansen-Juselius maximum likelihood co-integration test (Johansen, 1991) we need to perform some preliminary tests to estimate the optimum length of interruption in vector autoregressive (VAR) method. In fact, it is quite possible to choose Akaike and Schwarz Bayesian in VAR method to determine the optimum length of interruption.

Table 3

Non-stationary test results

\begin{tabular}{lll}
\hline Variable & Augmented Dicky-Fuller (ADF) & Critical value \\
\hline LNIP & -2.42 & -2.93 \\
LNIV & -1.44 & -2.93 \\
LNIM & -1.53 & -2.93 \\
LNIF & -2.71 & -2.93 \\
LNIH & -3.37 & -3.61 \\
LNMII & -3.25 & -3.62 \\
\hline
\end{tabular}

Table 4

Stationary test results

\begin{tabular}{llll}
\hline Variable & Augmented Dicky-Fuller (ADF) & Critical value & Level of significance \\
\hline D(LNIP) & -5.84 & -3.61 & $1 \%$ \\
D(LNIV) & -4.89 & -3.61 & $1 \%$ \\
D(LNIM) & -3.38 & -2.94 & $5 \%$ \\
D(LNIF) & -4.77 & -3.61 & $1 \%$ \\
D(LNIH) & -3.79 & -3.61 & $1 \%$ \\
D(LNMII) & -7.00 & -3.62 & $1 \%$ \\
\hline
\end{tabular}

\subsubsection{First stage computations}

In this stage, we need to determine the optimum length of interruption and our analysis indicates that based on two criteria of Akaike and Schwarz Bayesian optimum length of interruption is 2 and 1. On the other hand, LR statistics rejects IR(1) so we conclude that IR(2) represents a better value for VAR method.

\subsubsection{Johansen-Juselius maximum likelihood co-integration test}

In estimating co-integration, Johansen and Juselius differentiate between various cases. There are literally five cases for the proposed model of this paper. In the first case, the model is considered without intercept, the second model considers the model with intercept without considering time trend, the third case considers unconditional intercept without time trend, the fourth model unconditional intercept with time trend and finally the last model considers conditional intercept with unconditional time trend. 
It is not easy task to find the best model among these five models. Johansen suggests to consider all five methods and perform co-integration test and incase null hypothesis is rejected repeat this test until null hypothesis is rejected. Table 5 and Table 6 show details of our survey.

Table 5

The results of $\lambda_{\text {trace }}$

\begin{tabular}{llllllll}
\hline \multicolumn{2}{l}{ Hypothesis } & \multicolumn{2}{l}{$2^{\text {nd }}$ model } & \multicolumn{2}{l}{$3^{\text {rd }}$ model } & $4^{\text {th }}$ model & \\
\hline $\mathrm{H}_{0}$ & $\mathrm{H}_{1}$ & $\lambda_{\text {trace }}$ & Critical value & $\lambda_{\text {trace }}$ & Critical value & $\lambda_{\text {trace }}$ & Critical value \\
\hline$r=0$ & $r \geq 1$ & 85.09 & 53.48 & 64.70 & 48.88 & 84.43 & 63.00 \\
$r \leq 1$ & $r \geq 2$ & 50.44 & 34.87 & 30.38 & 31.54 & 45.41 & 42.34 \\
$r \leq 2$ & $r \geq 3$ & 23.03 & 20.18 & 5.53 & 17.86 & 16.89 & 25.77 \\
\hline
\end{tabular}

Table 6

The results of $\lambda_{\max }$

\begin{tabular}{llllllll}
\hline \multicolumn{2}{l}{ Hypothesis } & $2^{\text {nd }}$ model & \multicolumn{2}{l}{$3^{\text {rd }}$ model } & \multicolumn{2}{l}{$4^{\text {th }}$ model } \\
\hline $\mathrm{H}_{0}$ & $\mathrm{H}_{1}$ & $\lambda_{\max }$ & Critical value & $\lambda_{\max }$ & Critical value & $\lambda_{\max }$ & Critical value \\
\hline$r=0$ & $r=1$ & 34.65 & 28.27 & 34.33 & 27.42 & 39.02 & 31.79 \\
$r \leq 1$ & $r=2$ & 27.41 & 22.04 & 24.85 & 21.12 & 28.52 & 25.42 \\
$r \leq 2$ & $r=3$ & 19.64 & 15.87 & 5.46 & 14.88 & 12.19 & 19.22 \\
\hline
\end{tabular}

Based on the results we have for $\lambda_{\text {trace }}$ and $\lambda_{\max }$, we can find the most suitable model. In this case, the null hypothesis on $\mathrm{r}=0$ and the alternative hypothesis is $\mathrm{r}=1$. All $\lambda_{\text {trace }}$ and $\lambda_{\max }$ values are greater than critical values and null hypothesis on having no vector of co-integration vector is rejected. On the other hand, the third model represents a lower value for $\lambda_{\max }$ and we can conclude that this is the most suitable model for long term investigation.

\subsubsection{The normalized co-integration model}

We have investigated different models and the following represent the best fitted model,

$$
L N I P=0.81 L N I V+0.45 L N I M-0.16 L N M I I
$$

The results of the resulted model are consistent with what we observe from economical theories since we see a negative sign on instability variable. This means that when economical conditions become stable we could expect more investment. In other words, we see a positive relationship between value added and private investment since an increase of one percent in value added yields an increase of 0.81 percent in industry sector. In addition, an increase of one percent in loans dedicated to industry will increase private investment for about 0.45 percent.

\subsubsection{Modified ECM model}

As we have already explained, there are some co-integration among four variables of $L N I P, L N I V$, LNIM and LNMII. Therefore, there is a long-term relationship among them. To resolve this issue, we use the error terms from the long term fitted regression equation along with first order difference of other variables and their lags and perform a new regression function. The results is as follows, 


$$
\begin{aligned}
\text { DLNIP }= & 0.09+0.45 \text { DLNIP }_{t-1}+1.40 D L N I V_{t}+0.21 D \text { LNIM }_{t}-0.15 D \text { LNMII }_{t}-0.68 E C M_{t-1} \\
\text { t-student } & (-3.90) \quad(-3.09) \quad(1.15) \quad(2.44) \\
& \bar{R}^{2}=0.58 \quad \text { D.W. }=2.41 \quad \text { F-stat }=10.52
\end{aligned}
$$

Based on the achieved results and eliminating the variables whose coefficients are not statistically meaningful we can reach the following results,

$$
\begin{aligned}
\text { DLNIP }= & -0.07+0.45 D L N I P_{t-1}+1.45 D L N I V_{t}-0.13 D L N M I I_{t}-0.67 E^{2} M_{t-1} \\
\text { t-student } & (-3.82) \quad(-2.90) \quad(2.52) \\
& \bar{R}^{2}=0.58 \quad \text { D.W. }=2.47 \quad \text { F-stat }=12.69
\end{aligned}
$$

In Eq. (15), $D$ represents first order difference and the coefficient of ECM is equal to 0.67. Since Fvalue represents a meaningful value when the significance level is 0.05 and DW located within the acceptable limits we can accept the model. The results show that the short-term changes on LNIP with one lag and LNIV have positive impact on LNIP. In addition, any short term changes on LNMII has negative and meaningful impact on LNIP and approximately 0.67 percent of difference between the actual and long term are discounted in each period. The results indicate that instability index has negative effect even in short term on Iran's industry. This shows the relevant importance of instability on economy.

\section{Conclusion}

In this paper, we have presented an empirical analysis to study the effect of economical stability on the amount of investment coming from the private sector. We have calculated macroeconomics instability index (MII) using the methods developed by Fischer (1991), Fischer and Modigiliani (1993) and Bleaney (1996). We have also used Glezakos (1973) method, which considered long-term deviation of real values as instability index. Therefore, we have used four variables of inflation rate (TINF), the ratio of budget deficit on growth domestic product (GDP) (TBD), foreign debt on GDP (TFD) and the ratio of actual currency rate on nominate currency (TFD). The results show that the short-term changes on LNIP with one lag and LNIV have positive impact on LNIP. In addition, any short term changes on LNMII has negative and meaningful impact on LNIP and approximately 0.67 percent of the difference between the actual and long term are discounted in each period. The results indicate that instability index has negative effect even in short term on Iran's industry. This shows the relevant importance of instability on economy.

\section{Acknowledgment}

The authors would like to thank the anonymous referees for constructive comments on earlier version of this paper.

\section{References}

Andrés, J., \& Doménech, R. (2006). Automatic stabilizers, fiscal rules and macroeconomic stability. European Economic Review, 50(6), 1487-1506.

Agenor, P.B. (2000). The Economics of Adjustment and Growth. Academic Press.

Bleaney, M. F. (1996). Macroeconomic stability, investment and growth in developing countries. Journal of Development Economics, 48, 461-77.

Chang, W.Y., Tsai, H.F., \& Chang, J.J. (2011). Interest rate rules and macroeconomic stability with transaction costs. International Review of Economics \& Finance, 20(4), 744-749. 
Cox, G.M., \& Harvie, C. (2010). Resource price turbulence and macroeconomic adjustment for a resource exporter: A conceptual framework for policy analysis. Energy Economics, 32(2), 469-489

Fischer, S. (1991). Growth, Macroeconomics and Development. NBER Working Paper, No. 3702.

Fischer, S. \& Modigiliani, F. (1993). Toward an understanding of the real effects and costs of Inflation. Weltwirtschaftliches Archive, 114, 810-33.

Glezakos,C.(1973). Export instability and economic growth: A statistical verification. Economic Development and Cultural Change, 21(3), 670-678.

Johansen, S. (1991). Estimation and Hypothesis Testing of Cointegration Vectors in Gaussian Vector Autoregressive Models. Econometrica, 59, 1551-1580.

Morgan, P.J. (2011). The role of macroeconomic policy in rebalancing growth. Journal of Asian Economics, 23(1), 13-25

Pesola, J. (2011). Joint effect of financial fragility and macroeconomic shocks on bank loan losses: Evidence from Europe. Journal of Banking \& Finance, 35(11), 3134-3144.

World Bank (1993). The East Asian Economic Miracle: Economic Growth and Public Policy. Oxford University Press, Oxford, 105. 